\title{
Chemogenetic Suppression of Medial Prefrontal- Dorsal Hippocampal Interactions Prevents Estrogenic Enhancement of Memory Consolidation in Female Mice
}

\author{
(1) Jennifer J. Tuscher, ${ }^{*}{ }^{-}$Lisa R. Taxier, Jayson C. Schalk, Jacqueline M. Haertel, and ${ }^{\circ}$ Karyn M. Frick
}

https://doi.org/10.1523/ENEURO.0451-18.2019

Department of Psychology, University of Wisconsin-Milwaukee, Milwaukee, WI 53211

\section{Visual Abstract}
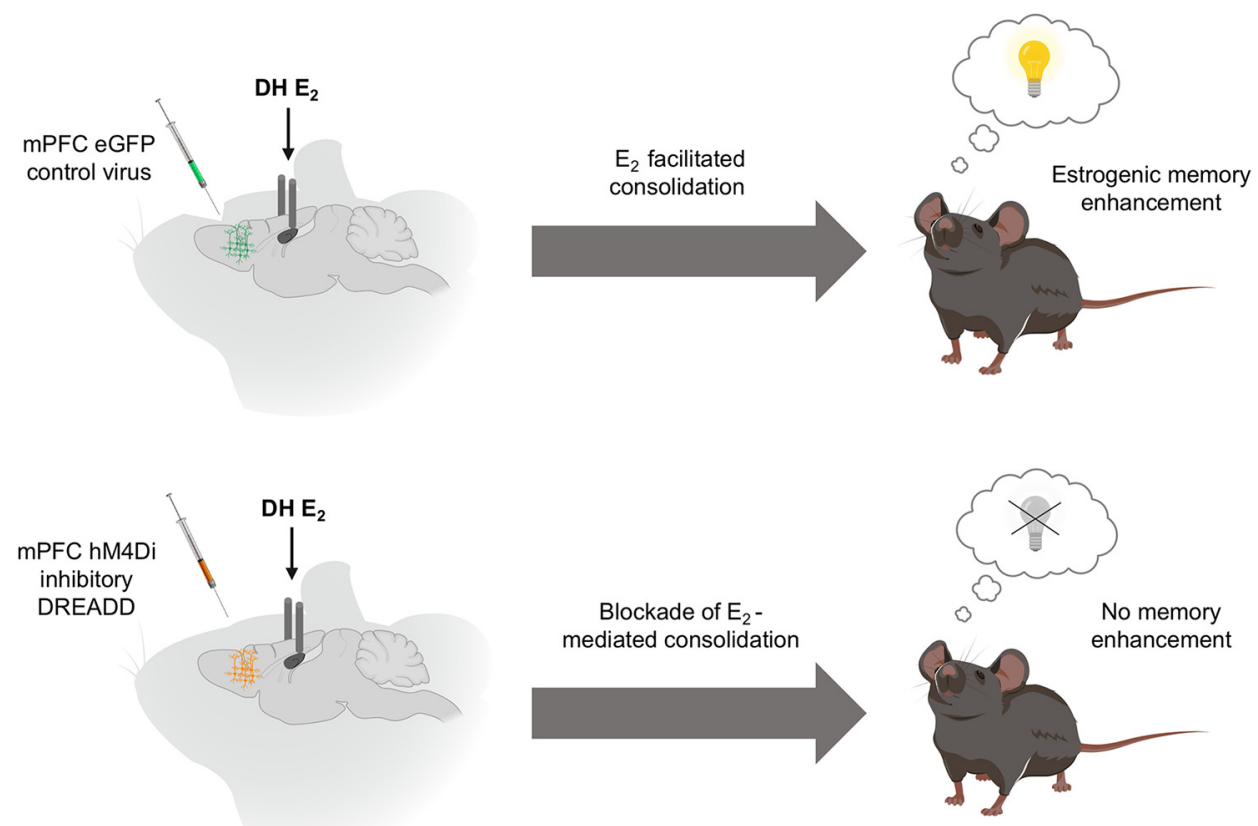

\section{Significance Statement}

Estrogens influence the prevalence and severity of certain psychiatric and neurodegenerative disorders, many of which are characterized by impaired medial prefrontal cortex (mPFC) and dorsal hippocampus (DH) function. Myriad findings demonstrate that $17 \beta$-estradiol $\left(E_{2}\right)$ regulates hippocampal plasticity and memory, however, far less is known about estrogenic regulation of other interconnected brain regions, like the mPFC. Here, we report that $\mathrm{mPFC} \mathrm{E}_{2}$ infusion in ovariectomized mice increases mPFC spine density and facilitates memory consolidation, and that chemogenetic inactivation of the mPFC blocks the memory-enhancing effects of $\mathrm{DH}$-infused $\mathrm{E}_{2}$. These findings suggest an essential role for the mPFC, alone and in concert with the $\mathrm{DH}$, in mediating the memory-enhancing effects of $\mathrm{E}_{2}$. Such circuit-level interactions may be critical to understanding how $\mathrm{E}_{2}$ regulates memory. 
The importance of the dorsal hippocampus $(\mathrm{DH})$ in mediating the memory-enhancing effects of the sexsteroid hormone $17 \beta$-estradiol $\left(\mathrm{E}_{2}\right)$ is well established. However, estrogen receptors (ERs) are highly expressed in other brain regions that support memory formation, including the medial prefrontal cortex (mPFC). The mPFC and DH interact to mediate the formation of several types of memory, and behavioral tasks that recruit the mPFC are enhanced by systemic $E_{2}$ administration, making this region a prime candidate for investigating circuit-level questions regarding the estrogenic regulation of memory. Further, infusion of $\mathrm{E}_{2}$ directly into the $\mathrm{DH}$ increases dendritic spine density in both the $\mathrm{DH}$ and mPFC, and this effect depends upon rapid activation of cell-signaling pathways in the $\mathrm{DH}$, demonstrating a previously unexplored interaction between the $\mathrm{DH}$ and mPFC that led us to question the role of the mPFC in object memory consolidation and the necessity of DH-mPFC interactions in the memory-enhancing effects of $E_{2}$. Here, we found that infusion of $E_{2}$ directly into the mPFC of ovariectomized mice increased mPFC apical spine density and facilitated object recognition and spatial memory consolidation, demonstrating that $E_{2}$ in the mPFC increases spinogenesis and enhances on memory consolidation. Next, chemogenetic suppression of the mPFC blocked the beneficial effects of $\mathrm{DH}$-infused $\mathrm{E}_{2}$ on memory consolidation, indicating that systems-level $\mathrm{DH}-\mathrm{mPFC}$ interactions are necessary for the memory-enhancing effects of $\mathrm{E}_{2}$. Together, these studies provide evidence that $\mathrm{E}_{2}$ in the mPFC mediates memory formation, and reveal that the $\mathrm{DH}$ and $\mathrm{mPFC}$ act in concert to support the memory-enhancing effects of $E_{2}$ in female mice.

Key words: DREADD; estradiol; hippocampus; mouse; prefrontal cortex; spine density

\section{Introduction}

Sex-steroid hormones have a broad impact on the neural circuitry that supports learning and memory, yet much remains unknown about the cellular and circuitlevel mechanisms through which they exert their effects. The potent estrogen $17 \beta$-estradiol $\left(\mathrm{E}_{2}\right)$ can regulate neuronal excitability and spinogenesis in the dorsal hippocampus (DH) and medial prefrontal cortex (mPFC), brain regions important for cognitive function that are compromised during aging and in numerous neuropsychiatric disorders (Godsil et al., 2013; Sampath et al., 2017). Memory consolidation, a process which requires coordinated effort between the hippocampus and mPFC, is facilitated by systemic injection or direct infusion of $E_{2}$ into the DH of female rodents (Tuscher et al., 2015). However, the specific mechanisms through which $\mathrm{E}_{2}$ en-

Received November 16, 2018; accepted March 26, 2019; First published April 1, 2019.

The authors declare no competing financial interests.

Author contributions: J.J.T. and K.M.F. designed research; J.J.T., L.R.T., J.C.S., and J.M.H. performed research; J.J.T. analyzed data; J.J.T., L.R.T., and K.M.F. wrote the paper.

This work was supported by the University of Wisconsin-Milwaukee College of Letters and Science, a Research Growth Initiative Award (101X334) from the University of Wisconsin-Milwaukee Research Foundation (K.M.F.), a University of Wisconsin-Milwaukee Advanced Opportunity Placement Fellowship (J.J.T.), a Sex and Gender in Alzheimer's Award (SAGA-17-419092) from the Alzheimer's Association (K.M.F.), the University of Wisconsin-Milwaukee Office of Undergraduate Research (J.C.S. and J.M.H.), and R01MH107886 (K.M.F.)

*J. T. Tuscher's present address: Department of Neurobiology, University of Alabama at Birmingham, Birmingham, AL 35294.

We thank Dr. Fred J. Helmstetter for the use of his Olympus Fluoview FV1200 confocal microscope and Dr. Patrick K. Cullen for technical assistance with the scope. We also thank Dr. James R. Moyer 3rd for the use of his Olympus BX51WI microscope and Ms. Vanessa Ehlers for technical assistance with this scope.

Correspondence should be addressed to Karyn M. Frick at frickk@uwm.edu. https://doi.org/10.1523/ENEURO.0451-18.2019

Copyright $(2019$ Tuscher et al.

This is an open-access article distributed under the terms of the Creative Commons Attribution 4.0 International license, which permits unrestricted use, distribution and reproduction in any medium provided that the original work is properly attributed. hances memory consolidation remain poorly understood, and little is known about how interactions between the $\mathrm{DH}$ and $\mathrm{mPFC}$ might contribute to estrogenic regulation of memory.

The object recognition (OR) and object placement (OP) tasks involve the integration of "what" and "where" components of memory, and are commonly used to assess episodic-like memory in rodents (Dere et al., 2005; Barker et al., 2017; Eichenbaum, 2017). Previous work has demonstrated that direct $\mathrm{DH}$ infusion of $\mathrm{E}_{2}$ immediately after object training can extend the delay at which ovariectomized mice can recall training objects or locations, and that this enhanced memory consolidation depends on $\mathrm{E}_{2}$-mediated activation of the extracellular signal-regulated kinase (ERK) and mammalian target of rapamycin (mTOR) cell-signaling pathways in the DH (Fernandez et al., 2008; Fortress et al., 2013). Recent research has also shown that $E_{2}$-induced increases in spinogenesis in both the $\mathrm{DH}$ and $\mathrm{mPFC}$ rely on activation of ERK and mTOR signaling in the DH (Tuscher et al., 2016a), highlighting putative systems-level interactions between these brain regions that may be important for memory formation in female rodents. However, the extent to which $\mathrm{DH}$ mPFC interactions are necessary for the memory enhancing effects of $E_{2}$ remains unknown. Moreover, the mPFC expresses all major estrogen receptor (ER) subtypes (Almey et al., 2014), suggesting $E_{2}$ may act directly in the $\mathrm{mPFC}$ to impact spinogenesis or enhance memory consolidation. The idea that $E_{2}$ may act within the mPFC to improve neuroplasticity and memory is further supported by studies showing systemic $E_{2}$ administration can increase mPFC spine density, alter glutamatergic synaptic transmission, and improve memory in tasks that involve the MPFC, including the radial arm maze, $Y$ maze, OR, and OP (Luine et al., 1998; Luine, 2016; VelazquezZamora et al., 2012; Galvin and Ninan, 2014).

Therefore, the present study sought to determine the extent to which $E_{2}$ can act directly in the MPFC to regulate object recognition and spatial memory consolidation, and 
the necessity of DH-mPFC interactions for the memoryenhancing effects of $\mathrm{DH} \mathrm{E}_{2}$ infusion. We first delivered $\mathrm{E}_{2}$ directly to the MPFC of ovariectomized mice immediately after object training to assess the effects of $E_{2}$ on episodic memory consolidation and spine density in the $\mathrm{mPFC}$ and $D H$. mPFC-infused $E_{2}$ increased mPFC apical spine density and enhanced object recognition and spatial memory consolidation, indicating that $E_{2}$ can act directly in the $\mathrm{mPFC}$ to regulate both dendritic morphology and memory formation. Next, we used designer receptors exclusively activated by designer drugs (DREADDs) to inactivate the mPFC immediately before $\mathrm{DH}-\mathrm{E}_{2}$ infusion to determine whether coordination between the DH and MPFC is necessary for $\mathrm{DH}$-infused $\mathrm{E}_{2}$ to enhance memory consolidation in ovariectomized mice. Chemogenetic suppression of the mPFC prevented $\mathrm{DH}$-infused $\mathrm{E}_{2}$ from enhancing both object recognition and spatial memory consolidation, suggesting that coordinated activity in the $\mathrm{DH}$ and $m P F C$ is necessary for $E_{2}$ to facilitate memory formation. These data provide evidence for a key role of the mPFC, and of DH-mPFC interactions, in the memory-enhancing effects of $E_{2}$ in ovariectomized mice.

\section{Materials and Methods}

\section{Subjects}

Female C57BL/6 mice were obtained from Taconic Biosciences at 9-12 weeks of age and were housed individually in a room with a 12/12 h light/dark cycle and ad libitum access to food and water. Experimenters conducting behavioral testing were blind to treatment status. All procedures were performed in accordance with the University of Wisconsin-Milwaukee Institutional Animal Care and Use Committee's regulations and are consistent with National Institutes of Health Guidelines for the Care and Use of Laboratory Animals.

\section{Surgery}

Mice were anesthetized with isoflurane $(5 \%$ for induction, $2 \%$ for maintenance) in $100 \%$ oxygen and then bilaterally ovariectomized and implanted with bilateral cannulae into the mPFC or DH as described previously (Kim et al., 2016; Tuscher et al., 2016b). DH-cannulated mice also received bilateral mPFC injections of DREADD virus as described below. Ovariectomy, cannulae implantation, and virus injections occurred during the same surgical session. For analgesia, mice received carprofen MediGel $1 \mathrm{~d}$ before surgery and subcutaneous injection of $5-\mathrm{mg} / \mathrm{kg}$ Rimadyl immediately after surgery.

\section{mPFC cannulation}

Immediately after ovariectomy, mice were implanted with stainless steel bilateral guide cannulae (Plastics One) aimed at the mPFC ( $n=12-13 /$ group; $1.8 \mathrm{~mm} \mathrm{AP,} \pm 0.3$ $\mathrm{mm} \mathrm{ML},-2.3 \mathrm{~mm} \mathrm{DV}$ ) and fixed to the skull with dental cement (Darby Dental Supply). Dummy cannulae were inserted into guide cannulae to prevent clogging. Mice recovered one week before behavioral testing.

\footnotetext{
MPFC DREADD delivery and DH cannulation

Immediately after ovariectomy, bilateral injections were made into the $\mathrm{mPFC}(n=9-11 / \mathrm{group} ; 1.9 \mathrm{~mm}$ AP, \pm 0.3
}

$\mathrm{mm} \mathrm{ML},-2.8 \mathrm{~mm}$ DV) using a $10 \mu \mathrm{l}$ Hamilton syringe, which was first lowered to $-2.8 \mathrm{~mm}$ ventral to the skull surface and held in place for $2 \mathrm{~min}$ to create a pocket for the first virus injection, as described previously (Tuscher et al., 2018). The syringe was then raised $0.1 \mathrm{~mm}$, and hM4Di DREADD virus (AAV-CamKIl $\alpha$-HA-hM4Di-IRESmCitrine, $2.1 \times 10^{12}$ particles $/ \mathrm{ml}$, serotype 8 , UNC Vector Core), eGFP control virus (AAV-CamKII $\alpha$-eGFP, $2.1 \times$ $10^{12}$ particles $/ \mathrm{ml}$, serotype 8 , UNC Vector Core), or saline (sham condition) was delivered using a syringe pump (KD Scientific) at a rate of $0.2 \mu \mathrm{l} / \mathrm{min}$ for $2 \mathrm{~min}$, for a total of 0.4 $\mu \mathrm{l} /$ infusion. The syringe was then raised $0.2 \mathrm{~mm}$, and a second infusion of the same volume was delivered at the same rate for a total of $0.8 \mu \mathrm{l} / \mathrm{hemisphere.} \mathrm{The} \mathrm{syringe}$ remained in place for $8 \mathrm{~min}$ for after each injection to allow for virus diffusion, and was then slowly retracted. Mice were then implanted with stainless steel bilateral guide cannulae aimed at the DH $(-1.7 \mathrm{~mm} \mathrm{AP}, \pm 1.5 \mathrm{~mm} \mathrm{ML}$, $-2.3 \mathrm{~mm} \mathrm{DV}$ ) as described previously (Tuscher et al., 2016a). Mice received presurgical and postsurgical analgesia as described above and were given three weeks for recovery and to allow sufficient time for viral expression before behavioral testing.

\section{Drugs and infusions}

Infusions into the mPFC or DH were conducted as described previously (Kim et al., 2016; Tuscher et al., $2016 b)$. Briefly, cyclodextrin-encapsulated $17 \beta-E_{2}$ (SigmaAldrich) was dissolved in sterile $0.9 \%$ saline to a concentration of $10 \mu \mathrm{g} / \mu \mathrm{l}$, and infused bilaterally into the $\mathrm{DH}$ or mPFC immediately after training. The vehicle, 2-hydroxypropyl- $\beta$-cyclodextrin (HBC; Sigma-Aldrich), was dissolved in saline to the same concentration of cyclodextrin present in the cyclodextrin-encapsulated $E_{2}$ solution. Infusions were conducted at a rate of $0.5 \mu \mathrm{l} / \mathrm{min}$ for $1 \mathrm{~min}$ per hemisphere as described previously (Fernandez et al., 2008; Fortress et al., 2013), resulting in a dose of $5-\mu \mathrm{g} \mathrm{E}_{2} /$ hemisphere.

For DREADD experiments, stock solutions of clozapine-N-oxide (CNO, Cayman Chemical) were prepared by dissolving CNO in $100 \%$ dimethyl sulfoxide (DMSO) at a concentration of $100 \mathrm{mg} / \mathrm{ml}$, and storing $10-\mu$ aliquots at $-20^{\circ} \mathrm{C}$, as described previously (Tuscher et al., 2018). On the day of injection, CNO stock was thawed and diluted to $1 \mathrm{mg} / \mathrm{ml}$ in a solution of sterile $0.9 \%$ saline containing $2 \%$ DMSO. Intraperitoneal injections of 1 - $\mathrm{mg} / \mathrm{kg}$ CNO were administered immediately after training, followed directly by bilateral $\mathrm{DH}$ infusion of vehicle or $\mathrm{E}_{2}$.

\section{Behavioral testing}

OR and OP protocols used to measure object recognition and spatial memory were conducted as described previously (Boulware et al., 2013; Fortress et al., 2013; $\mathrm{Kim}$ et al., 2016). Memory consolidation in both tasks is enhanced by $E_{2}$ and involves the DH (Tuscher et al., 2015). One week after mPFC cannula surgery or three weeks after DREADD/DH cannula surgery, mice were handled for $1 \mathrm{~min} / \mathrm{d}$ for $3 \mathrm{~d}$ before habituation. Mice were then habituated for two consecutive days by allowing them to explore the empty white arena $(60 \times 60 \times 47 \mathrm{~cm})$ 
for $5 \mathrm{~min} / \mathrm{d}$. During training, mice accumulated $30 \mathrm{~s} \mathrm{ex-}$ ploring two identical objects placed in the upper left and right corners of the arena. Time spent with the objects was recorded using ANY-maze tracking software (ANYmaze, RRID:SCR_014289). Immediately after training, mice were injected or infused as described above and then returned to their home cage. Post-training injections were used to pinpoint treatment effects to the memory consolidation period while minimizing potential confounding effects on performance factors (e.g., motivation, anxiety) on the measurement of memory consolidation (McGaugh, 1989; Frick and Gresack, 2003). OR memory was tested $48 \mathrm{~h}$ later; intact OR memory was demonstrated if the mice spent more time than chance (15 s) with the novel object during testing. OP training and testing were identical to OR, except that testing was conducted $24 \mathrm{~h}$ after training, and involved moving one of the identical training objects to a new location during testing. The 48-h and 24-h delays between training and testing in OR and $\mathrm{OP}$, respectively, were used because mice infused with $E_{2}$ into the $\mathrm{DH}$ demonstrate enhanced $\mathrm{OR}$ and $\mathrm{OP}$ memory consolidation at these time points (Tuscher et al., 2016b; Tuscher et al., 2018). All mice were trained and tested in both tasks with the order of testing counterbalanced such that half of the mice completed OR first and half completed OP first.

\section{Histologic verification of DREADD expression}

Three weeks after eGFP or DREADD virus surgeries, a subset of mice $(n=3)$ were anesthetized with isoflurane and perfused with $4 \%$ paraformaldehyde (PFA) in $1 \times$ PBS to confirm virus expression at the onset of behavioral training. Whole mouse brains were removed and postfixed in $1 \times$ PBS/4\% PFA overnight, followed by dehydration in a $1 \times \mathrm{PBS} / 30 \%$ sucrose solution. Tissue was sectioned on a cryostat $(40 \mu \mathrm{m})$ and free-floated in $1 \times$ PBS until it was mounted onto microscope slides (VWR) using aqueous mounting medium containing the nuclear stain DAPI (Santa Cruz). Fluorescent images were captured using an Olympus Fluoview FV1200 confocal microscope and accompanying software.

\section{Golgi staining and spine counting}

Two weeks after completion of behavioral testing, mice received mPFC infusions of $E_{2}$ or vehicle and were killed $2 \mathrm{~h}$ later to assess $\mathrm{E}_{2}$-mediated spine density changes in the $\mathrm{DH}$ and $\mathrm{mPFC}$. This time point was selected because $\mathrm{DH}$ infusion of $\mathrm{E}_{2}$ significantly increases dendritic spine density in both brain regions $2 \mathrm{~h}$ later (Tuscher et al., 2016a). Whole brains were collected and Golgi impregnation was performed as described previously (Frankfurt et al., 2011) using the Rapid GolgiStain kit (FD NeuroTechnologies). Briefly, secondary basal dendrites and tertiary apical dendrites were counted blindly from pyramidal neurons in CA1 and Layer II/III of the prelimbic region of the $\mathrm{mPFC}$. Dendrites from sex cells/region/brain were included in the analysis, and six to eight brains were quantified/group. Neurons were chosen for analysis if their cell bodies and dendrites were well impregnated, and dendrites were continuous and clearly distinguishable from adjacent cells. Spines were counted on an Olympus
BX51WI microscope under oil (100X) using Neurolucida version 11.08 (MBF Bioscience; RRID:SCR_001775). Spine density was calculated by dividing spine number by dendrite length, and data expressed as number of spines/ $10-\mu \mathrm{m}$ dendrite.

\section{Experimental design and statistical analysis}

Power analyses indicate that at least nine mice per group per behavioral experiment and nine mice/group per spine counting experiment will provide $90 \%$ power to detect small effect sizes at $p=0.05$, two-tailed. In the first experiment, ovariectomized mice were trained in OR and $\mathrm{OP}$, and then immediately received bilateral mPFC infusion of vehicle or $5 \mu \mathrm{g} / \mathrm{hemisphere} \mathrm{E}_{2}(n=10-13 / \mathrm{group})$ to determine the extent to which $E_{2}$ in the mPFC could regulate memory consolidation. Memory was tested $24 \mathrm{~h}$ (OP) or $48 \mathrm{~h}(\mathrm{OR})$ later. Two weeks after the conclusion of behavioral testing, mice received MPFC infusions of vehicle or $E_{2}$, and whole brains were collected $2 \mathrm{~h}$ later for Golgi staining and dendritic spine density analyses $(n=$ $6-8 /$ group). In the second experiment, a new set of ovariectomized mice were cannulated in the $\mathrm{DH}$ and injected with saline (sham) or an AAV8 viral vector containing eGFP control virus or the inhibitory hM4Di DREADD in the mPFC. A subset of mice ( $n=3 /$ group) injected with eGFP or hM4Di were perfused three weeks later to confirm virus expression at the initiation of behavioral testing. Immediately after behavioral training, mice were injected with $1-\mathrm{mg} / \mathrm{kg} \mathrm{CNO}$ and then received $\mathrm{DH}$ infusion of vehicle or $5 \mu \mathrm{g} /$ hemisphere $\mathrm{E}_{2}$. Memory was tested $24 \mathrm{~h}(\mathrm{OP})$ or 48 h (OR) later.

Statistical analyses were conducted using GraphPad Prism 6 software (RRID:SCR_002798). To determine whether learning occurred within each group, behavioral data were analyzed using one sample $t$ tests to assess whether the time each group spent exploring the novel (OR) or moved (OP) objects differed from chance (15 s; Tuscher et al., 2016b, 2018). This analysis was used because time spent with the objects is not independent; time spent with one object reduces time spent with the other (Frick and Gresack, 2003). Between-group comparisons were assessed with Student's $t$ tests or one-way ANOVA. Effects of mPFC vehicle and $E_{2}$ infusion were compared using Student's $t$ tests. For other experiments involving more than two treatment groups, betweengroup differences were measured using one-way ANOVAs with treatment as the independent variable, followed by Fisher's LSD post hoc tests when appropriate (Tuscher et al., 2016b, 2018). For spine density analyses, Student's $t$ tests were used to determine the effect of $\mathrm{E}_{2}$ treatment on spine density in each brain region, followed by post hoc tests when appropriate. Statistical significance was determined as $p \leq 0.05$.

\section{Results}

\section{mPFC $E_{2}$ infusion immediately after training enhances memory consolidation}

To determine whether $E_{2}$ can act directly in the mPFC to enhance memory consolidation, young female mice were ovariectomized and implanted with bilateral guide 
A Object Recognition

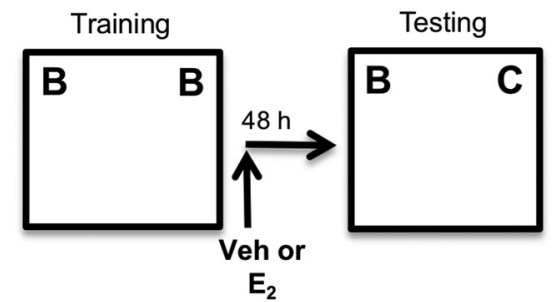

C

48 h Object Recognition

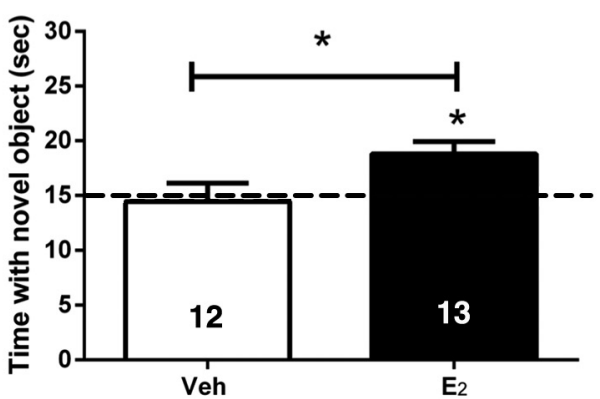

B Object Placement

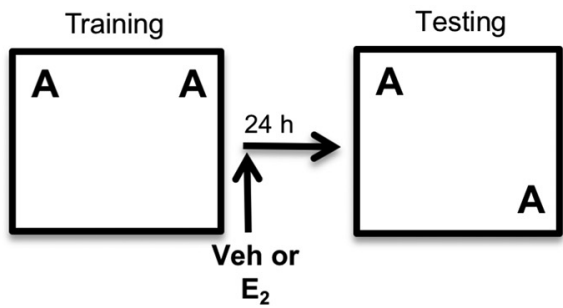

D

24 h Object Placement

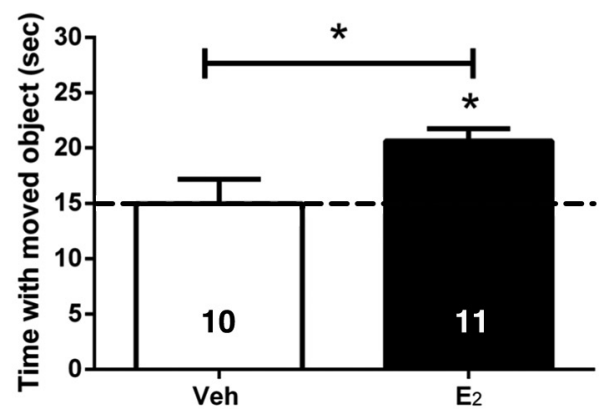

Figure 1. Infusion of $E_{2}$ into the mPFC immediately after training enhances memory consolidation. Mice infused with $E_{2}$ directly into the mPFC spent significantly more time than chance (dashed line at $15 \mathrm{~s}$ ) with the novel object $(\boldsymbol{A}, \boldsymbol{C})$ when tested $48 \mathrm{~h}$ after training, or with the moved object $(\boldsymbol{B}, \boldsymbol{D}) 24 \mathrm{~h}$ after training. Mice infused with vehicle (Veh) into the mPFC did not spend more time than chance with the novel or moved objects. These data suggest that $E_{2}$ can improve the consolidation of object memories by acting directly in the mPFC. Bars represent the mean \pm standard error of the mean (SEM); $* p<0.05$ relative to chance and the vehicle group $(n=$ 10-13/group).

cannulae aimed at the prelimbic region of the mPFC. One week later, mice were trained in the OR or OP tasks, and then immediately received bilateral mPFC infusion of vehicle or $5 \mu \mathrm{g} /$ hemisphere $\mathrm{E}_{2}$ ( $n=10-13 /$ group). OR memory was tested $48 \mathrm{~h}$ after training. Mice infused with $\mathrm{E}_{2}$ $\left(t_{(12)}=3.4, p=0.005\right)$, but not vehicle $\left(t_{(11)}=0.18, p=\right.$ $0.87)$, spent significantly more time than chance with the novel object during testing (Fig. $1 A, C$ ), indicating that only $\mathrm{E}_{2}$-infused mice displayed intact memory for the familiar training object. $E_{2}$-infused mice also spent significantly more time with the novel object than vehicle-infused mice $\left(t_{(23)}=2.294, p=0.03\right.$; Fig. $\left.1 C\right)$, suggesting that $E_{2}$ in the mPFC enhances OR memory consolidation. OP memory was tested $24 \mathrm{~h}$ after training. As in $\mathrm{OR}, \mathrm{E}_{2}$-treated mice spent significantly more time than chance with the moved object $\left(t_{(10)}=5.06, p=0.001\right)$, whereas vehicle-treated mice did not $\left(t_{(9)}=0.18, p=0.9\right.$; Fig. $\left.1 B, D\right)$. Moreover, $\mathrm{E}_{2}$-infused mice spent significantly more time with the moved object than vehicle-infused mice $\left(t_{(19)}=2.5, p=\right.$ 0.02 ; Fig. $1 D)$, indicating that $\mathrm{E}_{2}$ in the mPFC also enhances spatial memory consolidation. Together, these data demonstrate that direct infusion of $E_{2}$ in the mPFC enhances OR and spatial memory consolidation in ovariectomized female mice.

mPFC $E_{2}$ infusion increases mPFC, but not CA1, spine density $\mathbf{2} \mathrm{h}$ after infusion

Two weeks after the completion of behavioral testing, mice received $\mathrm{mPFC}$ infusions of vehicle or $\mathrm{E}_{2}$ as above, and whole brains were collected $2 \mathrm{~h}$ later for Golgi stain- ing and dendritic spine density analyses of the MPFC and CA1 of the $\mathrm{DH}$. We focused our analyses on Layers II/III of the mPFC and the CA1 subfield of the $\mathrm{DH}$, as previous research examining the impact of systemic $E_{2}$ injection, $E_{2}$ fluctuations across the estrous cycle, and ER agonists on spine density have identified these regions as being particularly sensitive to $E_{2}$ (Woolley et al., 1990; Woolley and McEwen, 1992; Phan et al., 2011; Frankfurt and Luine, 2015; Tuscher et al., 2016a). $E_{2}$ significantly increased mPFC apical $\left(t_{(12)}=2.89, p=0.014\right)$, but not basal $\left(t_{(11)}=\right.$ $1.11, p=0.28)$, spine density relative to vehicle $2 \mathrm{~h}$ after $\mathrm{mPFC}$ infusion (Fig. 2A,C). No significant differences were observed in CA1 apical $\left(t_{(12)}=0.88, p=0.4\right)$ or basal $\left(t_{(12)}\right.$ $=0.02, p=0.98)$ spine density between vehicle and $E_{2}$ mice after mPFC $E_{2}$ infusion (Fig. 2B). These findings demonstrate that $\mathrm{E}_{2}$ can increase apical spine density in the mPFC within $2 \mathrm{~h}$ of infusion, but does not impact CA1 spine density at this time point.

\section{Chemogenetic suppression of the MPFC immediately after training prevents $E_{2}$ in the $D H$} from enhancing memory consolidation

$\mathrm{DH}$ infusion of $\mathrm{E}_{2}$ increases dendritic spine density in the mPFC (Tuscher et al., 2016a), raising the possibility that the $\mathrm{DH}$ and mPFC might interact to mediate the memory-enhancing effects of $\mathrm{DH}_{2}$ infusion. To determine whether the mPFC is necessary for the memoryenhancing effects of $\mathrm{DH} \mathrm{E}_{2}$ infusion, we suppressed the activity of mPFC excitatory neurons using inhibitory 
A

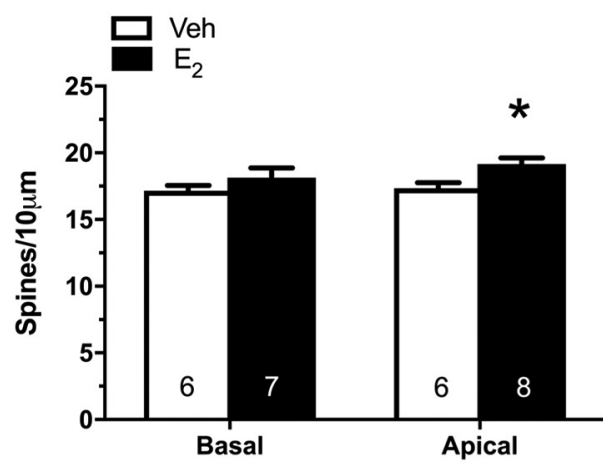

C

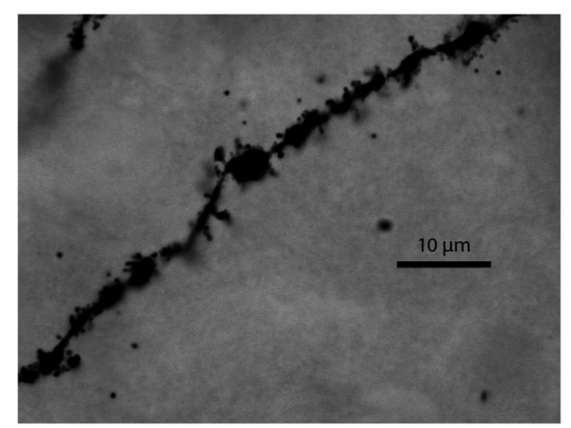

B CA1 Spines, $2 \mathrm{~h}$

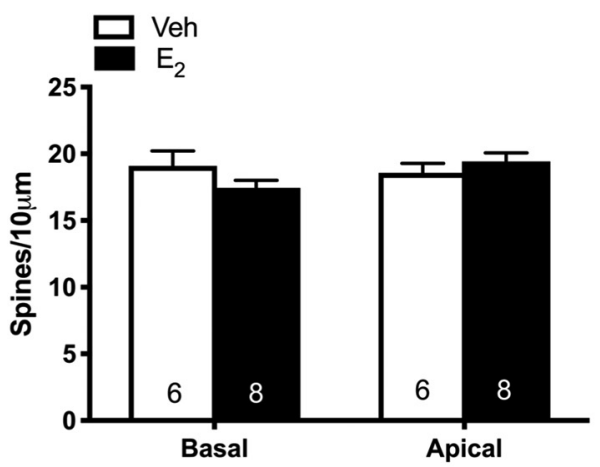

Estradiol

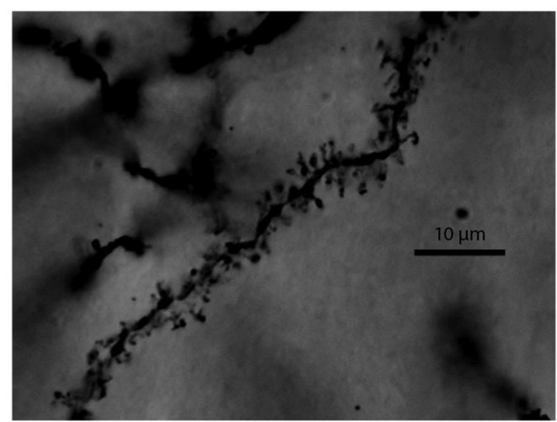

Figure 2. $\mathrm{mPFC} \mathrm{E}_{2}$ infusion increases apical spine density in the mPFC $2 \mathrm{~h}$ later. Relative to vehicle (Veh), apical but not basal, spine density was significantly increased in the mPFC $2 \mathrm{~h}$ after mPFC infusion of $5-\mu \mathrm{g} \mathrm{E}_{2}$ per hemisphere $(\boldsymbol{A})$. mPFC infusion did not alter apical or basal spine density in CA1 $2 \mathrm{~h}$ after mPFC infusion of $\mathrm{E}_{2}(\boldsymbol{B})$. Bars represent the mean $\pm \mathrm{SEM} ; * p<0.05$ relative to the vehicle group ( $n=6-8$ /group). C, Representative photomicrographs of Golgi-impregnated secondary apical dendrites from pyramidal cells in Layer II/III of the mPFC. Under oil 100x.

hM4Di DREADDs. Ovariectomized mice were implanted with bilateral $\mathrm{DH}$ guide cannulae, and bilaterally injected with saline (sham condition), or an AAV8 viral vector containing either eGFP or the hM4Di DREADD into the mPFC. This viral construct is driven by the CaMKIl $\alpha$ promoter, which allows for selective expression predominantly in excitatory neurons, and suppression of excitatory neural activity near the site of injection when bound by its ligand CNO (Armbruster et al., 2007; Zhu et al., 2014). The control construct AAV8-CaMKIl $\alpha$-eGFP, which is driven by the same promoter as that used for the DREADD virus but lacks the hM4Di gene (Zhu et al., 2014), was used to control for nonspecific virus effects. A subset of mice $(n=$ 3 /group) were perfused three weeks after surgery to verify that DREADD and eGFP control viruses were expressed in the $\mathrm{MPFC}$ at the initiation of behavioral training (Fig. 3). Expression of the eGFP control (Fig. $3 B, D$ ) and mCitrinelabeled hM4Di (Fig. 3A,C) viruses was localized to the mPFC, and was detected throughout the dorsal-ventral extent of the MPFC injection site, starting in the infralimbic region and extending throughout the prelimbic region and anterior cingulate in both eGFP control and DREADDexpressing mice, respectively.

After establishing viral expression, we next examined whether mPFC activity is necessary for the memory- enhancing effects of $E_{2}$ infused into the $\mathrm{DH}$. To address this question, we used a $1 \mathrm{mg} / \mathrm{kg}$ dose of CNO that does not impair memory consolidation on its own in ovariectomized female mice expressing mPFC-hM4Di DREADDs (Tuscher et al., 2018). Ovariectomized mice implanted with bilateral $\mathrm{DH}$ guide cannulae and injected with saline, eGFP, or hM4Di underwent behavioral training $(n=9-11$ / group). Immediately after training, mice were injected with $1-\mathrm{mg} / \mathrm{kg} \mathrm{CNO}$ and then received $\mathrm{DH}$ infusion of vehicle or $5 \mu \mathrm{g} /$ hemisphere $E_{2}$. DREADD-mediated suppression of the $\mathrm{mPFC}$ immediately after training prevented $E_{2}-$ mediated enhancement of OR memory. Specifically, Sham, eGFP, or hM4Di control groups receiving CNO+ Veh did not spend significantly more time than chance with the novel object when tested $48 \mathrm{~h}$ after $\mathrm{OR}$ training (sham: $t_{(10)}=1.85, p=0.09$; eGFP: $t_{(10)}=1.42, p=0.19$; hM4Di: $t_{(9)}=0.14, p=0.89$; Fig. $\left.4 A, C\right)$, suggesting a lack of intact OR memory in all groups infused with vehicle into the $\mathrm{DH}$. In contrast, sham and eGFP mice receiving $\mathrm{CNO}+\mathrm{E}_{2}$ remembered the familiar training object $48 \mathrm{~h}$ later (sham: $t_{(8)}=4.37, p=0.002$; eGFP: $t_{(8)}=2.78, p=$ 0.02 ; Fig. $4 C$ ), indicating that sham surgery and the eGFP construct did not prevent $\mathrm{DH}$-infused $\mathrm{E}_{2}$ from enhancing OR memory consolidation. Importantly, the hM4Di group receiving $\mathrm{CNO}+\mathrm{E}_{2}$ did not spend more time than chance 
A

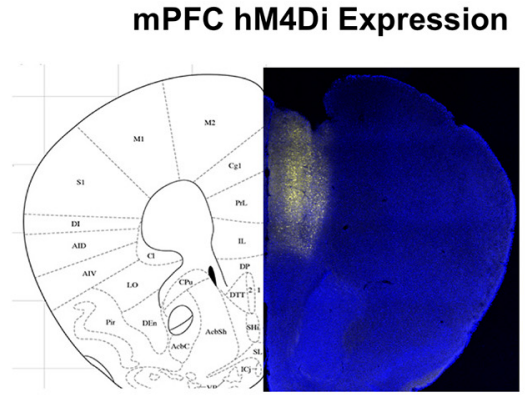

C

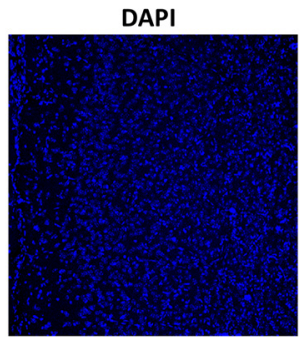

DAPI

D

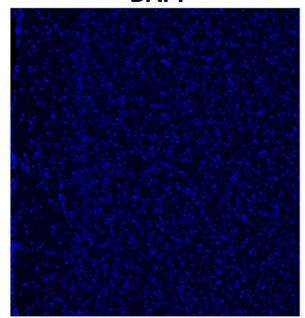

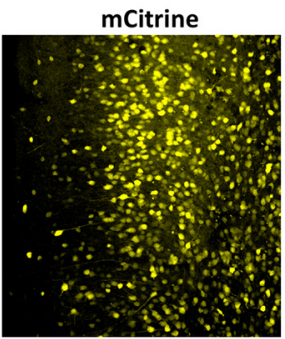

eGFP

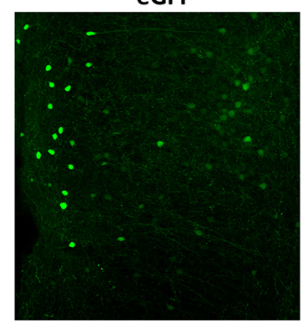

B

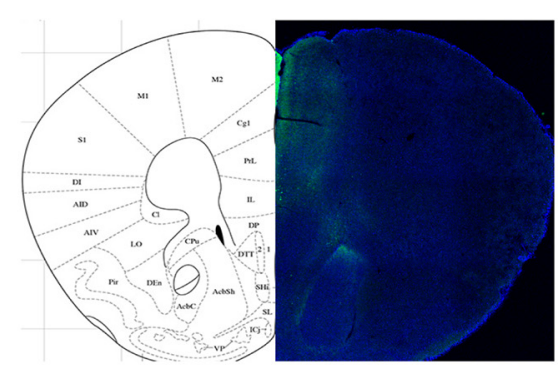

Merged
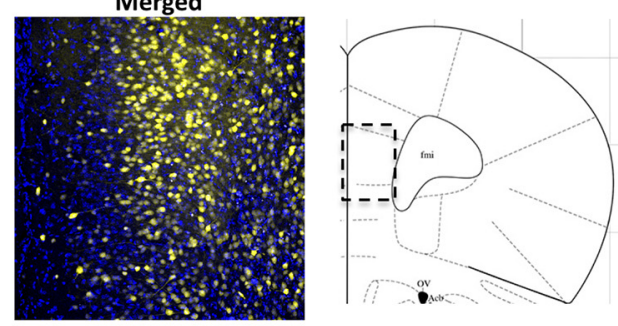

Merged

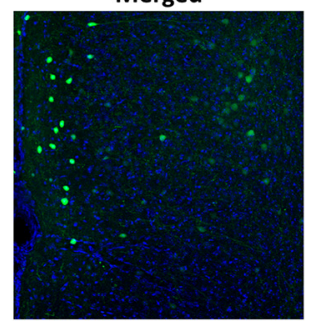

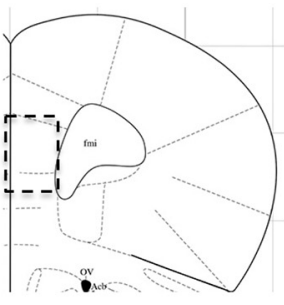

Figure 3. hM4Di and eGFP viral expression in the mPFC is present three weeks after injection. Coronal sections (40 $\mu \mathrm{m})$ of CaMKII $\alpha$-hM4Di-mCitrine DREADD $(\boldsymbol{A}, \boldsymbol{C})$ or CaMKII $\alpha$-eGFP control virus $(\boldsymbol{B}, \boldsymbol{D})$ in the mPFC of female mice three weeks after injection confirms virus expression throughout the mPFC. Blue puncta: DAPI, a marker of cell nuclei; yellow: mCitrine-tagged DREADD virus; green: eGFP-tagged control virus. Merged images provide additional spatial context for DREADD or control virus expression within the region of interest.

with the novel object (hM4Di: $t_{(9)}=0.94, p=0.37$; Fig. $4 C$ ) during testing, demonstrating that excitatory neural activity in the mPFC is necessary for $\mathrm{DH}$-infused $\mathrm{E}_{2}$ to enhance OR memory consolidation. These findings were further supported by one-way ANOVA, which demonstrated a significant main effect of treatment among the six groups $\left(F_{(5,54)}=5.14, p=0.001\right)$. Post hoc tests revealed that sham and eGFP groups receiving $\mathrm{DH}-\mathrm{E}_{2}$ infusions spent significantly more time with the novel object than $E_{2}$ treated hM4Di mice or any group infused with vehicle (ps $<0.05$; Fig. 4C).

To determine whether mPFC-DH interactions are also necessary for spatial memory consolidation, the same mice were tested in the OP task. OP training was conducted just as OR, although the order of testing varied among mice as described in Materials and Methods. Immediately after training, mice were injected with $1-\mathrm{mg} / \mathrm{kg}$ $\mathrm{CNO}$, followed by bilateral $\mathrm{DH}$ infusion of vehicle or 5 $\mu \mathrm{g} /$ hemisphere $E_{2}$. As with OR, we found that DREADDmediated suppression of excitatory neural activity in the mPFC immediately after training blocked $E_{2}$-mediated enhancement of OP memory consolidation. Sham, eGFP, and hM4Di control groups receiving $\mathrm{CNO}+$ Veh did not spend significantly more time than chance with the moved object when tested $24 \mathrm{~h}$ after OP training (sham: $t_{(9)}=$
$0.07, p=0.94$; eGFP: $t_{(9)}=0.56, p=0.591$; hM4Di: $t_{(9)}=$ $0.56, p=0.59$; Fig. $4 B, D$ ), suggesting that spatial memory was not intact in all vehicle-infused groups. In contrast, sham and eGFP mice receiving $\mathrm{CNO}+\mathrm{E}_{2}$ did spend significantly more time than chance with the moved object $24 \mathrm{~h}$ after training (sham: $t_{(9)}=7.50, p<0.0001$; eGFP: $t_{(9)}$ $=3.34, p=0.01$; Fig. $4 D$ ), indicating that $E_{2}$ enhanced spatial memory consolidation in both groups. However, as in $\mathrm{OR}, \mathrm{DH} \mathrm{E}_{2}$-mediated memory enhancement was suppressed in the hM4Di group receiving $\mathrm{CNO}+\mathrm{E}_{2}$, as this group did not spend more time than chance with the moved object (hM4Di: $t_{(9)}=0.13, p=0.90$; Fig. $4 D$ ) during testing. Similar to OR, this pattern of findings was further supported by a significant main effect of treatment $\left(F_{(5,54)}\right.$ $=2.79, p=0.03$; Fig. $4 D$ ) and post hoc tests revealed that sham or eGFP mice receiving $D H E_{2}$ infusion spent significantly more time with the moved object than hM4Di mice infused with $E_{2}$, or sham mice infused with vehicle (ps < 0.05; Fig. 4D). Together, these data suggest that mPFC neural activity is necessary for $E_{2}$ infused into the $\mathrm{DH}$ to enhance spatial and OR memory consolidation in ovariectomized mice, which illustrates the importance of systems-level coordination for the memory-enhancing effects of $E_{2}$ in females. 
A Object Recognition
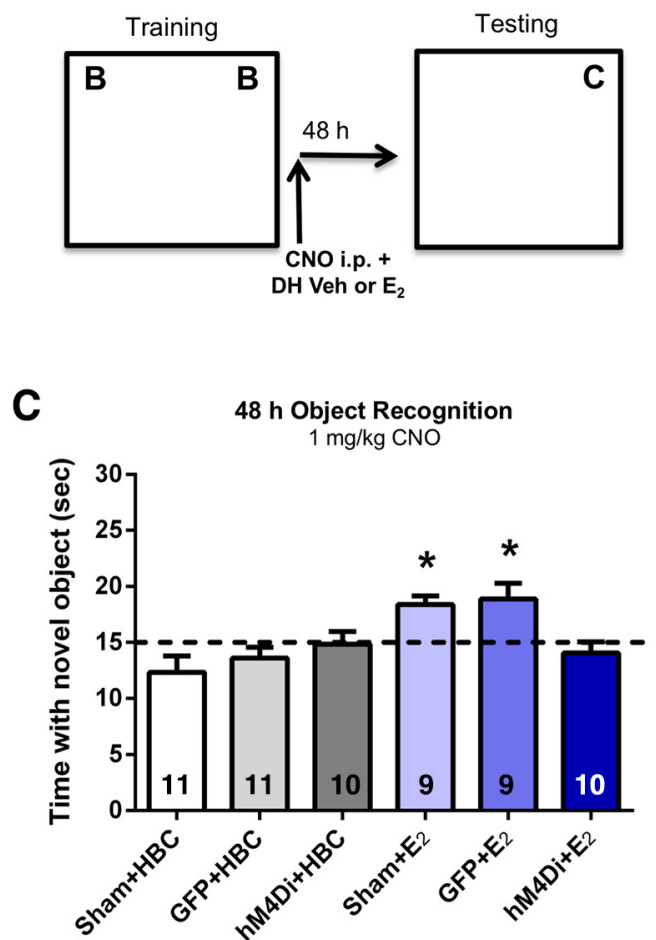

B Object Placement
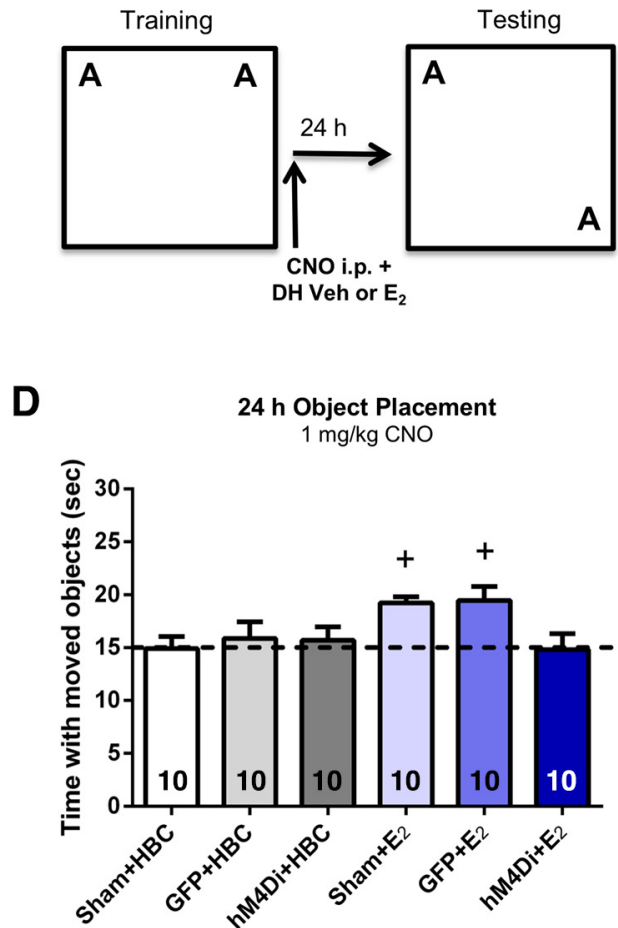

Figure 4. Chemogenetic suppression of the mPFC immediately after training prevents the memory enhancement induced by $\mathrm{DH} \mathrm{E}_{2}$ infusion. Sham, eGFP, or hM4Di control groups receiving CNO+Veh did not spend significantly more time than chance (15 s) with the novel object when tested $48 \mathrm{~h}$ after OR training $(\boldsymbol{A}, \boldsymbol{C})$ or with the displaced object $(\boldsymbol{B}, \boldsymbol{D}) 24 \mathrm{~h}$ after training. In contrast, sham or eGFP mice receiving $\mathrm{CNO}+\mathrm{E}_{2}$ immediately after training did spend significantly more time than chance with the moved and novel objects, displaying intact OP and OR memory. However, hM4Di mice treated with $\mathrm{CNO}+\mathrm{E}_{2}$ immediately after training did not demonstrate intact memory, suggesting that DREADD-mediated suppression of the mPFC blocks the beneficial mnemonic effects of DH-infused $\mathrm{E}_{2}$. Bars represent the mean $\pm \mathrm{SEM} ; * p<0.05$ relative to chance, all Veh-infused groups, and the $\mathrm{hM} 4 \mathrm{Di}-\mathrm{E}_{2}$ group ( $\left.n=9-11 / \mathrm{group}\right)$; $+p<0.05$ relative to chance and the Sham +Veh-infused and hM4Di- $\mathrm{E}_{2}$ groups $(n=9-11 / \mathrm{group})$.

\section{Discussion}

The hippocampus has been the focal point of much neuroendocrinology research examining how $\mathrm{E}_{2}$ mediates memory formation and neuroplasticity. However, $E_{2}$ also impacts other brain regions important for regulating cognitive function in females, including the mPFC, amygdala, striatum, and perirhinal cortex (Zurkovsky et al., 2007; Gervais et al., 2013; Maeng et al., 2017). Here, we found that $\mathrm{mPFC}$ infusion of $\mathrm{E}_{2}$ significantly increased mPFC apical spine density and enhanced both OR and spatial memory consolidation. These data are the first to demonstrate that $\mathrm{E}_{2}$ can act directly within the mPFC to facilitate memory consolidation and spinogenesis in female mice. Our findings are consistent with previous work demonstrating that $\mathrm{DH} \mathrm{E}_{2}$ infusion enhances memory consolidation and increases dendritic spine density in the $\mathrm{DH}$ and mPFC within 2 h (Fernandez et al., 2008; Fortress et al., 2013; Tuscher et al., 2016a). Moreover, the extent to which $\mathrm{E}_{2}$ infusion into the mPFC influences memory consolidation and spine density is similar to that observed after $\mathrm{DH} \mathrm{E}_{2}$ infusion in this study and previous work (Fortress et al., 2013; Tuscher et al., 2015, 2016a). Our data also align with previous reports of increased mPFC spine density and memory enhancement in the radial arm maze, $\mathrm{Y}$ maze, OR, and OP tasks after systemic $\mathrm{E}_{2}$ injection (Inagaki et al., 2012; Luine, 2016). However, the memory-enhancing effects of $E_{2}$ could not be directly attributed to actions within the mPFC in these studies, due to the systemic nature of delivery. Here, we found that direct $\mathrm{mPFC}_{2}$ infusion significantly enhanced memory and increased mPFC apical spine density, suggesting that the $\mathrm{mPFC}$ plays a critical role in $\mathrm{E}_{2}$-mediated memory enhancement. Although $\mathrm{DH}$ infusion of $\mathrm{E}_{2}$ significantly increased basal mPFC spine density $2 \mathrm{~h}$ after infusion in a previous study (Tuscher et al., 2016a), mPFC infusion of $\mathrm{E}_{2}$ in the present study did not reciprocally affect CA1 spine density $2 \mathrm{~h}$ later. These data may suggest that $\mathrm{DH}$ projections exert greater control over the mPFC than the $\mathrm{mPFC}$ exerts in return, or that mPFC input back to the $\mathrm{DH}$ is indirect or occurs over a longer timeframe. However, additional time points would need to be evaluated before concluding that mPFC input has no effect on $\mathrm{DH}$ spine density.

The specific mechanisms through which $E_{2}$ regulates memory and spinogenesis in the MPFC are currently unclear, as the pharmacological and chemogenetic approaches used in the present study do not allow for clear disambiguation between classical genomic and rapid 
non-classical actions of $E_{2}$. However, given the necessity of ERK activation for $\mathrm{E}_{2}$-mediated spine changes in cortical neurons (Srivastava et al., 2008), and the requirement of ERK and mTOR activation in the $\mathrm{DH}$ for $\mathrm{E}_{2}$-mediated memory enhancement and spinogenesis (Fernandez et al., 2008; Fortress et al., 2013; Tuscher et al., 2016a), we predict that rapid non-classical mechanisms are also likely critical for the mnemonic effects and spine changes observed after mPFC $E_{2}$ infusion. The observation that significant increases in mPFC spine density occur as early as $2 \mathrm{~h}$ after infusion (Fig. $2 A$ ) also supports the notion that these effects are mediated via the rapid non-classical mode of $E_{2}$ action, although this remains to be tested directly. Future studies involving the infusion of cellsignaling inhibitors directly into the $\mathrm{mPFC}$ in the presence of $\mathrm{E}_{2}$ will be necessary to more definitively discriminate between classical and non-classical mechanisms. The specific ERs mediating these effects also remain to be elucidated. $\mathrm{ER} \alpha, \mathrm{ER} \beta$, and G-protein-coupled ER (GPER) are all expressed throughout the mPFC (Almey et al., 2014), and recent work suggests that rapid $E_{2}$-induced hippocampal spinogenesis is mediated in part by $\mathrm{ER} \alpha$ and GPER (Phan et al., 2015). Therefore, these receptors are prime candidates for further examination.

In addition to the spine density changes observed in the mPFC after $\mathrm{E}_{2}$ infusion alone, there could be "additive" or "synergistic" effects of $\mathrm{E}_{2}$ and learning on spine density, as experience-induced changes have been observed in the mPFC (Kolb et al., 2008; Kolb and Gibb, 2015; Ouhaz et al., 2017), although not specifically after training in OR or OP. In the present study, we waited until two weeks after the completion of behavioral training to infuse our respective treatments, and infusions of vehicle or $E_{2}$ occurred in the absence of training immediately before tissue collection. Therefore, even if learning-induced spine changes occur after object training, and such theoretical changes persisted for two weeks after the completion of these tasks, this variable would be consistent across both vehicle and $\mathrm{E}_{2}$ treated groups. Therefore, it is unlikely that any additive effects between $E_{2}$ and learning would be observed in this dataset, as any potential experienceinduced increases would likely have occurred in both treatment groups. Nonetheless, the possibility remains of additive or synergistic effects between learning and $E_{2}$ on spine density, which could be investigated in future studies.

Our findings also demonstrate for the first time that mPFC neural activity is essential for the memoryenhancing effects of $\mathrm{DH} \mathrm{E}_{2}$ infusion, and illustrate a novel systems-level relationship between these brain regions in mediating the mnemonic effects of $E_{2}$. This notion is supported by our data demonstrating that suppressing neural activity in the mPFC with the inhibitory hM4Di DREADD immediately after training prevented $\mathrm{DH}$-infused $E_{2}$ from enhancing memory consolidation. The beneficial effects of $E_{2}$ on memory formation appear specific to the consolidation period, as previous research has shown that delayed systemic or $\mathrm{DH}$ administration of $\mathrm{E}_{2}$ (i.e., 1.5-3 $\mathrm{h}$ after training) does not enhance memory consolidation in the OR and OP tasks (Walf et al., 2006; Frye et al., 2007; Fernandez et al., 2008), suggesting $\mathrm{E}_{2}$ action during the first few hours after training is essential for memory consolidation. Thus, $\mathrm{E}_{2}$ 's effects in the $\mathrm{DH}$, and subsequent downstream interactions with other brain regions such as the mPFC after $\mathrm{DH} \mathrm{E}_{2}$ infusion, appear to facilitate memory specifically during the consolidation period, rather than during recall. This notion is consistent with previous work demonstrating that performance in a fear extinction task requiring the $\mathrm{MPFC}$ is facilitated when systemic $E_{2}$ is administrated immediately, but not $4 \mathrm{~h}$, after fear extinction training (Zeidan et al., 2011). Thus, although effects of post-training $E_{2}$ on recall cannot be entirely discounted in the present study, previous data make this explanation highly unlikely.

To ensure that our observed effect on memory consolidation reflected DREADD-mediated suppression of the memory-enhancing effects of $E_{2}$, rather than DREADDmediated memory impairment in general, we used a dose of CNO that does not impair memory on its own in combination with mPFC-hM4Di DREADD expression (Tuscher et al., 2018), which was essential given recent findings showing that the CNO metabolite clozapine affects locomotion in rats at high doses (Gomez et al., 2017). The fact that chemogenetic disruption of the mPFC prevented the beneficial mnemonic effects of $\mathrm{DH}$-infused $\mathrm{E}_{2}$ suggests that these regions coordinate during object memory consolidation, and lend further behavioral relevance to the $\mathrm{E}_{2}$-mediated spine changes recently observed in the mPFC after DH $E_{2}$ infusion (Tuscher et al., 2016a). Moreover, this work suggests a new interpretation of previous reports showing that $\mathrm{DH}$ infusion of $\mathrm{E}_{2}$ enhances $\mathrm{OR}$ and spatial memory consolidation (Fernandez et al., 2008; Boulware et al., 2013; Fortress et al., 2013), as the present findings demonstrate the essential involvement not only of the $\mathrm{DH}$, but also of the mPFC. Examining these putative circuit-level interactions may hold the key to understanding how $\mathrm{E}_{2}$ regulates memory consolidation.

Many questions remain regarding how the hippocampus and mPFC might interact to facilitate memory consolidation. Tract tracing studies support the existence of several potential routes of communication between the hippocampus and mPFC, including direct unilateral projections from dorsal CA1 and subiculum to the mPFC (Hoover and Vertes, 2007), unilateral projections between the ventral hippocampus and subiculum to the mPFC (Ferino et al., 1987; Jay et al., 1989; Jay and Witter, 1991; Cenquizca and Swanson, 2007), and indirect reciprocal connections routed through the nucleus reuniens of the thalamus or lateral entorhinal cortex (Burwell and Amaral, 1998; Hoover and Vertes, 2007; Vertes et al., 2007). Evidence for the functional relevance of these connections is supported by electrophysiological studies demonstrating that stimulation in the ventral CA1/subiculum of anesthetized rats results in stable long-term potentiation (LTP) in prefrontal neurons (Laroche et al., 1990; Jay et al., 1992). LTP between hippocampal and prefrontal synapses leads to a persistent increase in synaptic strength in awake behaving rats (Jay et al., 1996), suggesting the existence of direct excitatory input from the hippocampus to the mPFC. Other evidence suggests that temporally-co- 
ordinated neuronal activity occurs between the hippocampus and mPFC during periods of wakefulness and sleep in rodents, and that this synchronous activity is essential for memory consolidation (Jones and Wilson, 2005; Hyman et al., 2010; Sigurdsson et al., 2010; Schwindel and McNaughton, 2011). As such, it follows that chemogenetic suppression of the mPFC in the present study may have disrupted functional connectivity between the $\mathrm{DH}$ and mPFC, thereby disrupting systemslevel processes through which $E_{2}$ facilitates memory consolidation in female mice.

Although the mechanisms through which these circuitlevel changes occur are currently unclear, $\mathrm{DH}$-infused $\mathrm{E}_{2}$ may promote the transcription of activity-dependent genes in projection regions such as the $\mathrm{mPFC}$, and DREADD-mediated mPFC suppression might prevent these alterations from occurring. The idea that neuronal activity in the $\mathrm{DH}$ can alter gene expression in projection regions essential for memory formation is supported by at least two recent studies. In one, disruption of $\mathrm{DH}$ input to the mPFC during fear conditioning prevented later reactivation of putative mPFC engram cells and traininginduced increases in mPFC spine density (Kitamura et al., 2017). In another study, injection of Arc antisense oligonucleotides into the $\mathrm{DH}$ blocked fear reactivation-induced increases in neural activity markers (e.g., Arc, pCREB, and pCofilin) in both the $\mathrm{DH}$ and $\mathrm{mPFC}$, and prevented reactivation-induced enhancement of fear memory expression (Ye et al., 2017). Further, DREADD-mediated inhibition of $\mathrm{DH}$ projection terminals in the mPFC before reactivation sessions also prevented reactivation-induced increases in fear memory expression and memoryassociated proteins in the mPFC (Ye et al., 2017). Both studies indicate that inhibiting either neural activity or translation of neural activity markers within the $\mathrm{DH}$ alters cellular activity and spine density in the mPFC, and that disruption of these processes during consolidation impairs long-term memory. These findings are consistent with previous reports that ERK or mTOR inhibition in the $\mathrm{DH}$ are necessary for $\mathrm{DH}$-infused $\mathrm{E}_{2}$ to enhance memory consolidation and increase mPFC spinogenesis in ovariectomized mice (Fernandez et al., 2008; Fortress et al., 2013; Tuscher et al., 2016a). Together, these findings provide evidence that molecular processes in the $\mathrm{DH}$ (e.g., cell-signaling activation, protein translation) influence the mPFC. The present findings expand on this work by demonstrating that disrupting mPFC-DH interactions prevents $\mathrm{DH} \mathrm{E}_{2}$ from facilitating memory consolidation. These data collectively support a model in which $\mathrm{DH}$ infusion of $E_{2}$ increases excitatory input to the mPFC, which then drives activity-dependent changes in gene expression and/or protein translation essential for spinogenesis and memory consolidation. Chemogenetic suppression of neural activity in the mPFC may blunt the $\mathrm{E}_{2}$-induced increase in excitatory input, thereby preventing potential synaptic connections between the $\mathrm{DH}$ and mPFC from being strengthened after $E_{2}$ infusion, which in turn could prevent estrogenic enhancement of memory consolidation.
In sum, converging lines of research support a role for estrogenic modulation of hippocampal physiology, neuroplasticity, and memory consolidation. However, ERs are expressed in numerous brain regions, including the $\mathrm{mPFC}$, that act in concert with the hippocampus to modulate cognitive function. Here, we provide evidence that $\mathrm{E}_{2}$ within the mPFC can also regulate MPFC spine density and facilitate memory consolidation in female mice, and that $\mathrm{E}_{2}$-mediated enhancement of memory requires communication between the DH and mPFC. Such work provides key insights into how the hippocampus coordinates with other brain regions to facilitate the estrogenic regulation of memory. Further, given that coordination between the hippocampus and PFC is compromised in several psychiatric disorders and neurodegenerative diseases for which females are at greater risk (i.e., depression, post-traumatic stress disorder (PTSD), Alzheimer's disease (AD); Tolin and Foa, 2006; Dye et al., 2012; Godsil et al., 2013; Albert et al., 2015; Sampath et al., 2017), this work also provides a critical foundation for dissecting the circuit-level basis of certain mental health disorders, and may aid in the development of systems-level therapeutic strategies.

\section{References}

Albert K, Pruessner J, Newhouse P (2015) Estradiol levels modulate brain activity and negative responses to psychosocial stress across the menstrual cycle. Psychoneuroendocrinology 59:14-24.

Almey A, Cannell E, Bertram K, Filardo E, Milner TA, Brake WG (2014) Medial prefrontal cortical estradiol rapidly alters memory system bias in female rats: ultrastructural analysis reveals membraneassociated estrogen receptors as potential mediators. Endocrinology 155:4422-4432

Armbruster BN, Li X, Pausch MH, Herlitze S, Roth BL (2007) Evolving the lock to fit the key to create a family of $G$ protein-coupled receptors potently activated by an inert ligand. Proc Natl Acad Sci USA 104:5163-5168.

Barker GR, Banks PJ, Scott H, Ralph GS, Mitrophanous KA, Wong LF, Bashir ZI, Uney JB, Warburton EC (2017) Separate elements of episodic memory subserved by distinct hippocampal-prefrontal connections. Nat Neurosci 20:242-250.

Boulware MI, Heisler JD, Frick KM (2013) The memory-enhancing effects of hippocampal estrogen receptor activation involve metabotropic glutamate receptor signaling. J Neurosci 33:1518415194.

Burwell RD, Amaral DG (1998) Perirhinal and postrhinal cortices of the rat: interconnectivity and connections with the entorhinal cortex. J Comp Neurol 391:293-321.

Cenquizca LA, Swanson LW (2007) Spatial organization of direct hippocampal field CA1 axonal projections to the rest of the cerebral cortex. Brain Res Rev 56:1-26.

Dere E, Huston JP, De Souza Silva MA (2005) Integrated memory for objects, places, and temporal order: evidence for episodic-like memory in mice. Neurobiol Learn Mem 84:214-221.

Dye RV, Miller KJ, Singer EJ, Levine AJ (2012) Hormone replacement therapy and risk for neurodegenerative diseases. Int J Alzheimers Dis 2012:258454.

Eichenbaum H (2017) Prefrontal-hippocampal interactions in episodic memory. Nat Rev Neurosci 18:547-558.

Ferino F, Thierry AM, Glowinski J (1987) Anatomical and electrophysiological evidence for a direct projection from Ammon's horn to the medial prefrontal cortex in the rat. Exp Brain Res 65:421-426.

Fernandez SM, Lewis MC, Pechenino AS, Harburger LL, Orr PT, Gresack JE, Schafe GE, Frick KM (2008) Estradiol-induced enhancement of object memory consolidation involves hippocampal 
extracellular signal-regulated kinase activation and membranebound estrogen receptors. J Neurosci 28:8660-8667.

Fortress AM, Fan L, Orr PT, Zhao Z, Frick KM (2013) Estradiolinduced object recognition memory consolidation is dependent on activation of mTOR signaling in dorsal hippocampus. Learn Mem 20:147-155.

Frankfurt M, Luine V (2015) The evolving role of dendritic spines and memory: interaction(s) with estradiol. Horm Behav 74:28-36.

Frankfurt M, Salas-Ramirez K, Friedman E, Luine V (2011) Cocaine alters dendritic spine density in cortical and subcortical brain regions of the postpartum and virgin female rat. Synapse 65:955961.

Frick KM, Gresack JE (2003) Sex differences in the behavioral response to spatial and object novelty in adult C57BL/6 mice. Behav Neurosci 117:1283-1291.

Frye CA, Duffy CK, Walf AA (2007) Estrogens and progestins enhance spatial learning of intact and ovariectomized rats in the object placement task. Neurobiol Learn Mem 88:208-216.

Galvin C, Ninan I (2014) Regulation of the mouse medial prefrontal cortical synapses by endogenous estradiol. Neuropsychopharmacology 39:2086-2094.

Gervais NJ, Jacob S, Brake WG, Mumby DG (2013) Systemic and intra-rhinal-cortical $17-\beta$ estradiol administration modulate objectrecognition memory in ovariectomized female rats. Horm Behav 64:642-652.

Godsil BP, Kiss JP, Spedding M, Jay TM (2013) The hippocampalprefrontal pathway: the weak link in psychiatric disorders? Eur Neuropsychopharmacol 23:1165-1181.

Gomez JL, Bonaventura J, Lesniak W, Mathews WB, Sysa-Shah P, Rodriguez LA, Ellis RJ, Richie CT, Harvey BK, Dannals RF, Pomper MG, Bonci A, Michaelides M (2017) Chemogenetics revealed: DREADD occupancy and activation via converted clozapine. Science 357:503-507.

Hoover WB, Vertes RP (2007) Anatomical analysis of afferent projections to the medial prefrontal cortex in the rat. Brain Struct Funct 212:149-179.

Hyman JM, Zilli EA, Paley AM, Hasselmo ME (2010) Working memory performance correlates with prefrontal-hippocampal theta interactions but not with prefrontal neuron firing rates. Front Integr Neurosci 4:2.

Inagaki T, Frankfurt M, Luine V (2012) Estrogen-induced memory enhancements are blocked by acute bisphenol $A$ in adult female rats: role of dendritic spines. Endocrinology 153:3357-3367.

Jay TM, Witter MP (1991) Distribution of hippocampal CA1 and subicular efferents in the prefrontal cortex of the rat studied by means of anterograde transport of Phaseolus vulgarisleucoagglutinin. J Comp Neurol 313:574-586.

Jay TM, Glowinski J, Thierry AM (1989) Selectivity of the hippocampal projection to the prelimbic area of the prefrontal cortex in the rat. Brain Res 505:337-340.

Jay TM, Thierry AM, Wiklund L, Glowinski J (1992) Excitatory amino acid pathway from the hippocampus to the prefrontal cortex. Contribution of AMPA receptors in hippocampo-prefrontal cortex transmission. Eur J Neurosci 4:1285-1295.

Jay TM, Burette F, Laroche S (1996) Plasticity of the hippocampalprefrontal cortex synapses. J Physiol Paris 90:361-366.

Jones MW, Wilson MA (2005) Theta rhythms coordinate hippocampal-prefrontal interactions in a spatial memory task. PLoS Biol 3:e402.

Kim J, Szinte JS, Boulware MI, Frick KM (2016) $17 \beta$-estradiol and agonism of G-protein-coupled estrogen receptor enhance hippocampal memory via different cell-signaling mechanisms. J Neurosci 36:3309-3321.

Kitamura T, Ogawa SK, Roy DS, Okuyama T, Morrissey MD, Smith LM, Redondo RL, Tonegawa S (2017) Engrams and circuits crucial for systems consolidation of a memory. Science 356:73-78.

Kolb B, Cioe J, Comeau W (2008) Contrasting effects of motor and visual spatial learning tasks on dendritic arborization and spine density in rats. Neurobiol Learn Mem 90:295-300.
Kolb B, Gibb R (2015) Plasticity in the prefrontal cortex of adult rats. Front Cell Neurosci 9:15.

Laroche S, Jay TM, Thierry AM (1990) Long-term potentiation in the prefrontal cortex following stimulation of the hippocampal CA1/ subicular region. Neurosci Lett 114:184-190.

Luine V (2016) Estradiol: mediator of memories, spine density and cognitive resilience to stress in female rodents. J Ster Biochem Mol Biol 160:189-195.

Luine VN, Richards ST, Wu VY, Beck KD (1998) Estradiol enhances learning and memory in a spatial memory task and effects levels of monoaminergic neurotransmitters. Horm Behav 34:149-162.

Maeng LY, Cover KK, Taha MB, Landau AJ, Milad MR, Lebrón-Milad K (2017) Estradiol shifts interactions between the infralimbic cortex and central amygdala to enhance fear extinction memory in female rats. J Neurosci Res 95:163-175.

McGaugh JL (1989) Dissociating learning and performance: drug and hormone enhancement of memory storage. Brain Res Bull 23: 339-345.

Ouhaz Z, Ba-M'hamed S, Bennis M (2017) Morphological, structural, and functional alterations of the prefrontal cortex and the basolateral amygdala after early lesion of the rat mediodorsal thalamus. Brain Struct Funct 222:2527-2545.

Phan A, Lancaster KE, Armstrong JN, MacLusky NJ, Choleris E (2011) Rapid effects of estrogen receptor alpha $\alpha$ and $\beta$ selective agonists on learning and dendritic spines in female mice. Endocrinology 152:1492-1502.

Phan A, Suschkov S, Molinaro L, Reynolds K, Lymer JM, Bailey CD, Kow LM, MacLusky NJ, Pfaff DW, Choleris E (2015) Rapid increases in immature synapses parallel estrogen-induced hippocampal learning enhancements. Proc Natl Acad Sci USA 112: 16018-16023.

Sampath D, Sathyanesan M, Newton SS (2017) Cognitive dysfunction in major depression and Alzheimer's disease is associated with hippocampal-prefrontal cortex dysconnectivity. Neuropsychiatr Dis Treat 13:1509-1519.

Schwindel CD, McNaughton BL (2011) Hippocampal-cortical interactions and the dynamics of memory trace reactivation. Prog Brain Res 193:163-177.

Sigurdsson T, Stark KL, Karayiorgou M, Gogos JA, Gordon JA (2010) Impaired hippocampal-prefrontal synchrony in a genetic mouse model of schizophrenia. Nature 464:763-767.

Srivastava DP, Woolfrey KM, Jones KA, Shum CY, Lash LL, Swanson GT, Penzes P (2008) Rapid enhancement of two-step wiring plasticity by estrogen and NMDA receptor activity. Proc Natl Acad Sci USA 105:14650-14655.

Tolin DF, Foa EB (2006) Sex differences in trauma and posttraumatic stress disorder: a quantitative review of 25 years of research. Psychol Bull 132:959-992.

Tuscher JJ, Fortress AM, Kim J, Frick KM (2015) Regulation of object recognition and object placement by ovarian sex steroid hormones. Behav Brain Res 285:140-157.

Tuscher JJ, Luine V, Frankfurt M, Frick KM (2016a) Estradiolmediated spine changes in the dorsal hippocampus and medial prefrontal cortex of ovariectomized female mice depend on ERK and mTOR activation in the dorsal hippocampus. J Neurosci 36: 1483-1489.

Tuscher JJ, Szinte JS, Starrett JR, Krentzel AA, Fortress AM, Remage-Healey L, Frick KM (2016b) Inhibition of local estrogen synthesis in the hippocampus impairs hippocampal memory consolidation in ovariectomized female mice. Horm Behav 83:60-67.

Tuscher JJ, Taxier LR, Fortress AM, Frick KM (2018) Chemogenetic inactivation of the dorsal hippocampus and medial prefrontal cortex, individually and concurrently, impairs object recognition and spatial memory consolidation in female mice. Neurobiol Learn Mem 156:103-116.

Velazquez-Zamora DA, Garcia-Segura LM, Gonzalez-Burgos I (2012) Effects of selective estrogen receptor modulators on allocentric working memory performance and on dendritic spines in medial 
prefrontal cortex pyramidal neurons of ovariectomized rats. Horm Behav 61:512-517.

Vertes RP, Hoover WB, Szigeti-Buck K, Leranth C (2007) Nucleus reuniens of the midline thalamus: link between the medial prefrontal cortex and the hippocampus. Brain Res Bull 71:601-609.

Walf AA, Rhodes ME, Frye CA (2006) Ovarian steroids enhance object recognition in naturally cycling and ovariectomized, hormone-primed rats. Neurobiol Learn Mem 86:35-46.

Woolley CS, McEwen BS (1992) Estradiol mediates fluctuation in hippocampal synapse density during the estrous cycle in the adult rat. J Neurosci 12:2549-2554.

Woolley CS, Gould E, Frankfurt M, McEwen BS (1990) Naturally occurring fluctuation in dendritic spine density on adult hippocampal pyramidal neurons. J Neurosci 10:4035-4039.
Ye X, Kapeller-Libermann D, Travaglia A, Inda MC, Alberini CM (2017) Direct dorsal hippocampal-prelimbic cortex connections strengthen fear memories. Nat Neurosci 20:52-61.

Zeidan MA, Igoe SA, Linnman C, Vitalo A, Levine JB, Klibanski A, Goldstein JM, Milad MR (2011) Estradiol modulates medial prefrontal cortex and amygdala activity during fear extinction in women and female rats. Biol Psychiatry 70:920-927.

Zhu H, Pleil KE, Urban DJ, Moy SS, Kash TL, Roth BL (2014) Chemogenetic inactivation of ventral hippocampal glutamatergic neurons disrupts consolidation of contextual fear memory. Neuropsychopharmacology 39:1880-1892.

Zurkovsky L, Brown SL, Boyd SE, Fell JA, Korol DL (2007) Estrogen modulates learning in female rats by acting directly at distinct memory systems. Neuroscience 144:26-37. 